\title{
EL KEYNESIANISMO DESDE LA ÓPTICA DE LOS PAÍSES ATRASADOS: SU ADAPTACIÓN POR MANUEL DE TORRES A LA ECONOMÍA ESPAÑOLA *
}

JUAN ZABALZA

Universidad de Alicante

\section{RESUMEN}

El siguiente trabajo se propone estudiar la introducción del keynesianismo en España a través de los escritos de Manuel de Torres, probablemente el más activo de los economistas que adoptaron de una u otra forma la nueva doctrina en la posguerra. Dada la escasez en España de una reflexión teórica original, el artículo prestará especial atención a la adaptación que realiza Torres de las ideas keynesianas al contexto de la economía española. En particular, las ideas keynesianas contribuyeron decisivamente a sustituir la vía agraria defendida por Torres como camino de desarrollo de la economía española por el industrialismo que sostiene en la posguerra. El artículo ofrece las claves de esta evolución doctrinal y reivindica el papel de las ideas económicas como poderoso instrumento de transformación.

$N$ de E.: Fecha de recepción del artículo: junio, 2002.

Fecha de aprobación por el Consejo de Redacción: mayo, 2003.

* Una versión previa de este trabajo se presentó en la II Reunión de la Asociación Ibérica de Historia del Pensamiento Económico (Oporto, 14-15 de diciembre de 2001). Se han incorporado al mismo los comentarios que suscitó de José Luis Cardoso, Mario Gómez Olivares y Manuel Jesús González. Debo agradecer de manera muy especial las numerosas sugerencias que he recibido de Salvador Almenar, las cuales han sido decisivas de cara a perfilar la versión definitiva del mismo. También se han tenido presentes los comentarios de Enrique Fuentes Quintana, Ernest Lluch, Carlos Barciela, José Luis Cardoso y Vicent Llombart, miembros del Tribunal de la Tesis doctoral que sirvió de punto de arranque a la elaboración de este artículo. Por último, deseo agradecer la colaboración del Profesor Jesús Astigarraga y las sugerencias de dos evaluadores anónimos. 


\section{ABSTRACT}

The main aim of the article is to analyse the introduction of keynesianism into Spain through the Manuel de Torres' works, the most active proponent of the new doctrine during the forties and fifties. The article focus on the adaptation to the Spanish context of the Keynes's ideas by Manuel de Torres. In particular, Keynesianism contributed to replace the agrarian ideas defended by Torres in the thirties by a new interest in industrial development during the 40's and 50's. Thus, the article provides an explanation of Torres' doctrinal evolution and vindicates the role played by the economic ideas as an instrument of transformation. These ideas contributed to change the Torres perception of the Spanish economic reality.

JEL Classification: B22, B31, E12, N14.

En los últimos años la historiografía sobre la difusión internacional de las ideas económicas ha experimentado un importante impulso (Colander y Coats, 1989). A ello ha contribuido la proliferación de historias nacionales del pensamiento económico en países en que la ciencia económica no había alcanzado un alto grado de desarrollo (Almodóvar y Cardoso, 1998). En estos países la escasa originalidad teórica obligó a la adaptación de doctrinas del exterior que, asimiladas, respondian a las exigencias requeridas por las distintas realidades económicas, perfilando la reflexión de los economistas ${ }^{1}$. Entre las distintas doctrinas, la difusión internacional del keynesianismo ha suscitado una especial atención de los historiadores de la economía ${ }^{2}$.

En España, los estudios disponibles acerca de la difusión del keynesianismo ofrecen una primera aproximación de carácter panorámico ${ }^{3}$. Las primeras noticias del economista británico llegaron a principios de los años veinte a raiz de la publicación de The Economic Consequences of the Peace (1921). Durante los años treinta, en el debate periodístico que tuvo lugar

1 Véase Cardoso (1994), Cardoso y Lluch (1999), Lluch (1980, 1999).

2 AAVV (1984), Abraham-Frois y Larbre (1997), Bastien y Cardoso (1997), Bini y Magliulo (1998), Hall (1989), Pasinetti y Schefold (1999), Psalidopoulos (1996). Al igual que el término «neoclasicismo», la expresión «keynesianismo» ha sido utilizada por los economistas de formas diversas. Desde los que la identifican estrictamente con la doctrina del propio Keynes, hasta los que en un sentido más amplio la emplean para referirse a toda la literatura económica hermanada con las tesis del economista inglés, es decir, además de la de sus discípulos, la de economistas que sin pertenecer al círculo de Keynes ofrecían un planteamiento alternativo a la economía «neoclásica». Los términos «keynesiano» o «keynesianismo» se emplean en esta ocasión en su segundo y más amplio sentido (Beaud y Dostaler, 1995, pp. 50-51).

${ }^{3}$ Almenar (1983, 1997, 1999, 2001, 2002), Beltrán (1993), Velarde (1983, 1988). 
en la prensa diaria en torno a la política de obras públicas, se acudió con cierta frecuencia a la autoridad de Keynes y entre los economistas profesionales tuvo un cierto eco la publicación de Treatise on Money $(1930)^{4}$. Sin embargo, The General Theory of Employment, Interest and Money (1936), el trabajo que a la postre sería el punto de referencia para las generaciones posteriores de economistas, publicado en febrero de 1936, apenas pudo ser conocido antes de la Guerra Civil por un reducido grupo de economistas. Hay que esperar a la mitad de los años cuarenta para ver publicados los primeros y meritorios trabajos teóricos de carácter keynesiano 5 . Sin embargo, salvo puntuales excepciones, no puede hablarse de una reflexión teórica de alto nivel y, por tanto, la recepción del key. nesianismo en España debe contemplarse, preferentemente, desde la óptica de la economía aplicada y de la política económica. Al menos eso parece revelar tanto la atención prestada a las disputas sobre las políticas de pleno empleo - el llamado White Paper del Gobierno británico y el plan Beveridge-, como el debate en torno a la aplicación de The General Theory (1936) a los problemas de desarrollo de España que tuvo lugar en las páginas de la revista De Economia (Fuentes Quintana, 1951).

Manuel de Torres fue uno de los impulsores de la introducción de la doctrina keynesiana en España desde varios puntos de vista. De una parte, Torres fue el autor de la primera contribución teórica de carácter keynesiano publicada en España. Teoría General del Multiplicador (1943) es un intento quizás demasiado pretencioso de integrar el «multiplicador» de la inversión de Keynes y el «acelerador» de Harrod con el fin de explicar la «totalidad del ciclo económico». De otra, desde la dirección de la sección de economía de la editorial Aguilar, promovió la traducción de un conjunto de textos fundamentales de la órbita keynesiana que carecían de versión castellana, algunos de los cuales habían contribuido a cincelar su propio pensamiento -Hicks (1950), Andersen (1946), Pedersen (1945), Philip (1949) y Schneider $(1949,1958)$-.

Esta participación de Torres en la difusión del keynesianismo ya había sido señalada por otros estudiosos ${ }^{6}$. No obstante, en este artículo se pre-

4 Almenar (1997, pp. 15-16), Sánchez Arbós (1935).

5 Los más significativos son: Cano Denia (1948), Figueroa (1947), Sánchez Ramos (1945), Torres (1943).

${ }^{6}$ Cotorruelo (1976), Fuentes Quintana (1976), González (1990), Velarde (1974, 1978, 1990). Sobre Torres existe además una monografía (Zabalza, 1995), una tesis doctoral inédita (Zabalza, 1998) y un trabajo que interpreta sus ideas hacendísticas (Zabalza, 1998a). 
tende mostrar que, aunque la primera aproximación de Torres a la teoría keynesiana vino motivada por su interés en la explicación teórica de las fluctuaciones cíclicas, avanzada la década de los cuarenta, adaptó dicha doctrina como fundamento analítico de una estrategia de desarrollo económico industrialista. Naturalmente, la aceptación de la industrialización como estrategia de desarrollo para los países «atrasados» como España, supuso una inflexión fundamental en su pensamiento económico, puesto que en la década de los treinta defendía una «vía agraria» de desarrollo para la economía española. Las próximas líneas tratan de demostrar que la principal responsabilidad de esta evolución corresponde a las nuevas posibilidades y espacios, anteriormente inexistentes, abiertos por la propia doctrina keynesiana. Por último, el trabajo pondrá en evidencia la correspondencia entre el esfuerzo teórico de Torres, sus escritos sobre la economía española y la multitud de iniciativas que abanderó a lo largo de la década de los cincuenta.

\section{DEL AGRARISMO DE LOS AÑOS TREINTA AL INDUSTRLALISMO DE LA POSGUERRA. DOS MODELOS DE ACUMULACIÓN DE CAPITAL}

La adaptación del keynesianismo por Manuel de Torres se ensambla en una trayectoria intelectual que se inicia en los años treinta. Por entonces, Torres, ayudante en la Cátedra de Economía Política que ocupaba Zumalacárregui en la Universidad de Valencia, estaba vinculado a la Derecha Regional Valenciana, grupo político comprometido en la defensa de los «intereses» económicos de la agricultura de exportación valenciana ${ }^{7}$. Torres

${ }^{7}$ En los círculos económicos valencianos era de uso común la expresión «industrias naturales» para designar aquellas industrias competitivas que no necesitaban recurrir a la protección y que, por tanto, quedaban excluidas de sus críticas (Villalonga, 1980, pp. 124-125; Torres, 1935). Sin embargo, las denominadas «industrias artificiales» o industrias muy protegidas, entre las que se incluían las de abonos nitrogenados cuyos productos formaban parte de los costes de producción de los cultivos de regadio, eran el blanco de los ataques de los exportadores agrarios. La oposición al proteccionismo integral e industrial de la Restauración y la Dictadura había inclinado a los grupos vinculados a la exportación agrícola en Valencia hacia posiciones librecambistas. Éste era el caso de la Derecha Regional Valenciana y de su principal líder, Luis Lucia. Al comienzo de los años treinta, Manuel de Torres, también militante de dicho partido, diseñó una estrategia alternativa a los sectores librecambistas del partido, que se proponía defender los «intereses» económicos de la agricultura valenciana (Zabalza, 1995, pp. 24-26). 
pensaba, por influencia del economista italiano Luigi Einaudi, que el proceso de acumulación de capital en las sociedades capitalistas se sostenía sobre la capacidad de generación de ahorro privado que automáticamente se transformaba en inversión (Meacci, 1988). La formación de ahorro se vinculaba a la generación de beneficios; por tanto, exigía un nivel de precios que, a juicio de Torres, las fuerzas del mercado eran incapaces de alcanzar por sí mismas.

Torres empleaba como marco analítico una noción del equilibrio general inspirada por Enrico Barone y que había aprendido en los escritos del economista agrario italiano Arrigo Serpieri. Barone, en su conocido artículo «Il ministro della produzione nello Stato Collettivista» (1908), publicado en Giomale degli Economisti, había ideado una teoría del equilibrio general que sustituía el subastador walrasiano, metáfora del libre juego de las fuerzas del mercado, por una autoridad centralizada que establecía los precios de acuerdo a la programación económica. No obstante, la mayor parte de los elementos del sistema walrasiano quedaban preservados. Torres sintetizaba esta idea de la siguiente forma: «Una economía que reconozca estos dos principios fundamentales [la libertad de consumo y la libertad de elección de trabajo], cualesquiera que sean sus ulteriores diferencias, es una economía en la que todo el sistema de equilibrio está determinado por los precios» (Torres, 1935a). De este modo, Torres establecía el alcance y los límites de la intervención estatal, cuyo principal cometido, a su juicio, era el fomento del ahorro. En la actividad agraria, su principal objeto de estudio en los años treinta, la garantía de precios remuneradores de los productos agrícolas, la eliminación del doble gravamen del ahorro en la tributación personal -oponiéndose a la Ley Carner de 1932 - y el estímulo de las modalidades de cultivo del arrendamiento y, especialmente, de la aparcería, contribuirían a la consecución de dicho objetivo.

En este contexto, la solución de la denominada «cuestión social» agraria se reducía a resolver el problema técnico de la expansión de los regadios, dado que el desarrollo económico agrario bajo la modalidad de la aparcería, según Torres, no producía inestabilidad social. Esta concepción era común entre muchos agraristas españoles del período que atribuían a la extensión y progreso de la agricultura, la solución de los problemas sociales (Robledo, 1993). En particular, Torres estimaba que la aparcería era la modalidad de cultivo más adecuada para compatibilizar desarrollo económico agrario y estabilidad social, pues los altos beneficios se repartían, al compartir propietario y agricultor los riesgos económicos. En la agricultura valenciana 
de la década de los treinta, la aparcería era la modalidad de cultivo predominante en el secano, mientras que el arrendamiento imperaba en la producción de regadío (Calatayud, 1989). Sin duda, Torres pensaba que la extensión de los cultivos de productos agrarios de exportación debía estimularse a través del aumento de sus precios, que induciría a los aparceros a transformar los cultivos de secano en cultivos de regadío, una vez se dieran las condiciones previas de la transformación. Las raíces de este planteamiento son italianas. En concreto, la influencia de Arrigo Serpieri es de nuevo manifiesta ${ }^{8}$. En definitiva, Torres vinculaba desarrollo económico, «cuestión social» y marco institucional, en una velada pero frontal crítica al liberalismo económico y político, no exenta de una manifiesta predilección por la actividad agraria. Definía esta última actividad como un «modo de vida» con el fin de diferenciarla de la actividad industrial, cuyas consecuencias sociales como la proletarización, el enfrentamiento de clases o la desigualdad económica eran indeseables ${ }^{9}$.

Tras la Guerra Civil, esta concepción de la acumulación de capital y su aplicación a las particularidades de los países atrasados se modificó en algunos de sus términos de forma sustancial. Para comprender esta evolución hay que tener en cuenta tanto la influencia que ejercieron sobre Torres la lectura de The General Theory (1936) de Keynes y otros trabajos keynesianos, como la observación de la realidad desde la óptica de estas lecturas. El resultado fue una transición desde el agrarismo militante de los años treinta, hacia una nueva idea de desarrollo económico que, por una parte, se distanciaba del pensamiento industrialista «a ultranza» de los círculos de ingenieros del Ministerio de Industria y, por otra, del agrarismo demagógico y antiindustrialista de los primeros tiempos del franquismo (Velasco, 1984). La posición intermedia que Torres preconizaba situaba a la industria como motor del crecimiento económico. Sin embargo, la agricultura, lejos de quedar relegada a un plano secundario, contribuía a eliminar los impedimentos que en países atrasados como España planteaban los procesos de industrialización, en particular, la presión sobre la balanza de pagos.

Este nuevo marco analítico que comienza a fraguarse a mitad de la década de los cuarenta, es anunciado en los prólogos e introducciones de las monografías de la editorial Aguilar y alcanza su culminación y expre-

${ }^{8}$ Los trabajos de Serpieri que, a mi juicio, ejercieron una mayor influencia sobre Torres fueron Serpieri (1925, 1929, 1929a).

${ }^{9}$ Los testimonios son múltiples y particularmente claros en el Diario de Valencia, desde cuyas páginas encabezó una labor de adoctrinamiento a los sectores agrarios valencianos. 
sión más perfecta en Teoria de la política social (1949). La expresión «política social» es significativa, al situar en el centro de la discusión teórica la «cuestión social» con el carácter singular que tradicionalmente presentaba en España. Ahora, sin embargo, inspirándose en una idea contenida en el Capítulo XXIV de The General Theory (Keynes, 1973 [1936]), toma un perfil preciso al identificarse con una distribución de la renta injusta y vincularse con la teoría del ciclo económico y la industrialización. Sobre esta idea Torres construye su modelo analítico integrando elementos pertenecientes a distintas tradiciones teóricas.

\section{LAS CLAVES DE UNA EVOLUCIÓN INTELECTUAL}

Esta transformación de las ideas económicas de Torres se manifiesta en dos áreas. Una primera, de naturaleza metodológica, es la división del trabajo entre técnicos y economistas, que moderniza algunos de sus planteamientos epistemológicos del período anterior. Esta distinción, como se verá, pretendía crear un espacio para la crítica de la política económica en el marco del estado autoritario franquista. Una segunda, la introducción de elementos teóricos de cuño keynesiano, supone, por el contrario, una novedad absoluta. En efecto, Torres desarrolló un conjunto de argumentos, dispersos en varios escritos, que trataban de demostrar, a la luz de la teoría keynesiana, los beneficios de la industrialización en los países atrasados (Torres, 1950, 1955, 1956). El núcleo teórico de este nuevo planteamiento era la construcción de un modelo macroeconómico de distribución que permitía establecer los efectos económicos y sociales del proceso industrializador y su solución.

\section{La reflexión metodológica como requisito de la crítica de la política económica}

Las raíces del planteamiento metodológico de Torres se encuentran en el Ensayo sobre la naturaleza y significación de la Ciencia Económica, de Lionel Robbins, y en algunos escritos de Luigi Einaudi ${ }^{10}$. Estos trabajos contienen una perspectiva que subraya la estricta separación entre fines y medios en la política económica y la corréspondiente división de tareas entre políticos, que establecen los fines, y economistas, cuyas ocupaciones

\footnotetext{
${ }^{10}$ Robbins (1980 [1935]), Einaudi (1936).
} 
son propiamente técnicas. Torres había mantenido durante los años treinta una separación entre política y economía bajo otros presupuestos. En concreto, la fórmula «fines de la nación», expresaba que éstos se elevaban sobre los intereses particulares de sectores e individuos y estaban determinados en función de las características propias de cada país en un contexto de subordinación o predominio de la «Política» sobre la «Economía». Torres desarrolló estas ideas inspirado por la versión moderada de la ciencia económica corporativa etiquetada como la «terza via» e integrada por algunos de los más prestigiosos economistas italianos como Amoroso, Del Vecchio, De Stefani, Serpieri o Vito, entre otros. Estos economistas sostenían la necesidad de una nueva estructura estatal que habilitara al Estado para una intervención que permitiera superar la crisis económica, ante la pasividad que demostraba el sistema del laissez-faire. Sin embargo, no era un grupo rupturista con la economía neoclásica, pues no renunciaban a utilizar sus poderosos instrumentos analíticos ${ }^{11}$.

La reflexión de Robbins ofrecía un marco que superaba las debilidades de este planteamiento, al elevar a categoría científica la labor del economista. Este último, al restringirse al estudio de los medios, encontraba un ámbito de libertad para la crítica científica en el marco del Estado autoritario español de los años cuarenta y cincuenta, al asumir de forma aparentemente acrítica los objetivos de política económica prescritos por la autoridad política ${ }^{12}$. Esta metodología descartaba de forma voluntaria, y no por falta de reconocimiento de sus logros analíticos, los avances que en este momento se producían en el campo de la economía del bienestar tales como los test de compensación y la construcción de funciones de bienestar social. El coste de la elección de Torres fue significativo, pues la metodología fines-medios, tal como la adopta Torres, incurre en algunas contradicciones lógicas. La más evidente era la consideración de la redistribución de la renta como un fin y a la vez como un medio de la política económica para alcanzar el objetivo de pleno empleo, pues de acuerdo a la metodología fines-medios anteriormente descrita, los polí-

${ }^{11}$ El planteamiento metodológico y analítico de este grupo de economistas se puede consultar en Cavalieri (1994), Zagari (1982).

12 No obstante, en ocasiones no alcanzaba los resultados deseados, como demuestra la reacción que se produjo desde el periódico falangista Arriba, que respondió severamente a los planteamientos contenidos en la conferencia «La coordinación de la políticá económica» (Velarde, 1968, pp. 39-41). 
ticos determinaban los fines y los economistas los medios ${ }^{13}$. Sin embargo, conocedor de dichas limitaciones y debilidades, nunca hizo rectificación alguna durante la década de los cincuenta. Las razones parecen claras. Tanto en términos de inmunidad respecto al poder político como de eficiencia, la metodología «fines-medios» era superior en el marco de un Estado autoritario.

Esta opción metodológica se complementaba con la distinción entre efectos primarios y secundarios de la política económica. Esta operativa estaba inspirada directamente por el seminal trabajo de Jan Tinbergen, «Econometric Business Cycle Research», que introdujo el dinamismo en los modelos econométricos con el objeto de explicar el mecanismo del ciclo económico y las consecuencias de las medidas de política económica (Figueroa, 1965). En este trabajo, Tinbergen distinguía entre los efectos primarios o «impacto» y los efectos «secundarios» de la política económica, que formalizó matemáticamente en el sistema de Elementary Equations y gráficamente en el conocido Arrow Scheme (Tinbergen, 1939-1940). De este modo, la intervención del economista o técnico, capaz de prever los efectos «secundarios» de las medidas de política económica, era no sólo normativamente deseable, sino técnicamente imprescindible. Torres denominaba «teoría de la política económica» a los fundamentos analíticos de dicha intervención. Su consecuencia más inmediata era la «coordinación» de la política económica (Torres, 1950a, 1953).

\section{La nueva reflexión analítica}

\section{Keynesianismo e industrialización}

En la segunda mitad de la década de los cuarenta, comienza a detectarse en los escritos de Torres una progresiva aceptación de la industrialización como vía de desarrollo económico para España. Naturalmente, ello sig-

${ }^{13}$ El origen de la contradicción es la adopción de la rígida distinción de Robbins entre dos conjuntos, uno de fines y otro de medios, totalmente disjuntos. Todo hubiera sido más sencillo si, adoptando un enfoque más moderno, hubiera distinguido entre fines primarios, secundarios y terciarios y, paralelamente, entre políticas económicas primarias, secundarias y terciarias, de tal modo que un fin pudiera convertirse en medio para otro fin. Sin embargo, esto hubiera exigido eliminar la distinción de Robbins, pues el economista deberia asumir la responsabilidad de posicionarse respecto a los fines (Colm, 1965). Sin embargo, la estricta distinción de Robbins pertenecía al núcleo metodológico y teórico de Torres y era, por tanto, irrenunciable. 
nificaba una mutación fundamental en su pensamiento económico $\mathrm{y}$, en particular, en su teoría del desarrollo económico. No en vano, Torres empleć en sus explicaciones en la Facultad de Ciencias Políticas y Económicas de Madrid el tratado de comercio internacional de Gotfried Haberler, publicado en España en 1936, que expresaba serias dudas sobre la validez de la teoría del comercio internacional neoclásica (Velarde, 1990). No obstante, fue la influencia de The General Theory (1936) de Keynes la que le permitió entender la industrialización de los países atrasados como una estrategia de desarrollo económico. En efecto, poco después de publicarse Teoría de la política social (1949), Torres estimaba que la aplicación de la teoría keynesiana de la demanda efectiva al campo del comercio internacional era el fundamento de una nueva estrategia de desarrollo económico de los países con un cierto atraso económico: «la industrialización de los países atrasados, al elevar su renta real, tiende a promover el intercambio con los demás, llevándolo a un nivel absoluto más alto, aunque, en estas condiciones, el comercio internacional represente un porcentaje menor de la producción total» (Torres, 1950 , p. XVII) ${ }^{14}$. De este modo, Torres reemplazaba la división del trabajo que se deriva de la teoría neoclásica de la ventaja comparativa, por otra sugerida por la teoría de la demanda efectiva, que facultaba el desarrollo industrial de los países atrasados en el marco de la división internacional del trabajo.

El nuevo papel otorgado a la industria le ofrecía un espacio de maniobra suficiente para evitar el enfrentamiento frontal con las autoridades franquistas que perseguían el objetivo de «industrialización a ultranza» y que, de esta manera, Torres asumía en algunos de sus aspectos. Identificaba también los problemas específicos de la industrialización de estos países que exigían una constante vigilancia de la balanza de pagos con el objeto de evitar la insuficiencia de divisas (Torres, 1950). En el caso particular de España, Torres atribuía el origen de la escasez de divisas a la imperiosa necesidad de la industria española de importar materias primas y bienes industriales intermedios, cuya carencia causaba los habituales embotellamientos productivos.

${ }^{14}$ Esta cita procede de la «Introducción» al libro de Kurt Mandelbaum, La industrialización de los países atrasados (1950), que se tradujo al castellano cinco años después de su edición original inglesa por iniciativa de Torres. Este trabajo es considerado uno de los libros pioneros de la teoría moderna del desarrollo económico y ofrecía un enfoque keynesiano de este problema. 


\section{Las consecuencias sociales de la industrialización. Nuevo diagnóstico} y nuevo remedio

Pero la industrialización, y ello formaba parte del ideario de Torres desde los años treinta, conllevaba unos efectos sociales negativos. El nuevo procedimiento de agregación, característico del nuevo planteamiento keynesiano, permitió a Torres construir un modelo macroeconómico con el que se determinaba la distribución del producto total entre los diversos factores productivos y se analizaban los efectos económicos y sociales de la industrialización ${ }^{15}$. Por tanto, la singularidad de dicho modelo estribaba en la diferenciación de dos tipos de rentas en función del riesgo asumido en el proceso productivo por los distintos factores de producción. Por un lado, las rentas «residuales» como el beneficio, cuyo fundamento es la anticipación de las remuneraciones del resto de los factores de producción, caracterizadas, por tanto, porque los agentes que las perciben asumen riesgo; por otro, las rentas «contractuales» cuyos perceptores no lo asumen - salarios y renta del capital o interés-. Esta distribución microeconómica de la renta, cuya fuente remota es Risk, Uncertainty and Profit (1921) de Knigth, aunque también se encuentra en Pedersen (1945) y Schneider (1958 [1950]), adquiere, por medio de un esquema de flujo circular y un procedimiento de agregación análogo al empleado por Schneider, una dimensión macroeconómica ${ }^{16}$. En este contexto, el beneficio «funcional» se determina por medio de la siguiente ecuación:

${ }^{15}$ La taxonomía que ofrece Torres de los distintos tipos de distribución y redistribución de la renta parece original y completa. Dos categorías son interesantes desde el propósito de este trabajo. La «distribución funcional» o la atribución de renta a los distintos factores de producción en función de su posición en el proceso de producción en un marco macroeconómico, y la «distribución personal», o el resultado de asignar las rentas percibidas en el proceso de «distribución funcional» por los distintos factores de producción a los propietarios de los mismos. Análogamente Torres define la «redistribución funcional» que supone la manipulación de la asignación en el proceso de distribución funcional, como es el caso de una política de racionamiento y la «redistribución personal» que transfiere rentas de unos individuos a otros, tal como ocurre, por ejemplo, con los impuestos personales y las prestaciones que con ellos se financian (Torres, 1949, pp. 90-148).

${ }^{16}$ Pocos años más tarde, Torres señalaba que había utilizado para construir el diagrama de flujo circular algunos elementos extraídos de unos resúmenes de la «teoría del ecocírculo», cuyo autor, Ragnar Frisch, se los había enviado personalmente (Torres, 1953-1955, p. 41). Sin embargo, el examen del ecocirc-graph del Oslo Institute en la versión privada que también ofrece Tress, no revela ningún paralelismo con el diagrama de Torres. Tampoco se encuentra la distinción entre empresas productoras de bienes de consumo y de bienes de inversión en otros diagramas de flujo circular del período (Tress, 1948). 
$\mathrm{B}_{\mathrm{E}}$ : beneficio funcional.

$$
\mathrm{B}_{\mathrm{E}}=\mathrm{I}-\mathrm{S}^{17}
$$

I: inversión.

S: ahorro.

Pertrechado con esta ecuación del beneficio, Torres sostiene que la industrialización está asociada a un aumento de las inversiones y a un predominio de las industrias de bienes de inversión sobre las industrias de bienes de consumo. En consecuencia, la participación de las rentas residuales - como el beneficio- en el total de la renta aumenta. Puesto que la reciente teoría keynesiana del ciclo económico incorporaba la inversión pública como instrumento habitual de la política económica anticíclica, el aumento de la participación de los beneficios en la distribución de la renta quedaba asegurado. Parte de estos beneficios, consiguientemente, quedaban desvinculados del riesgo. A su juicio, esta distorsión respecto a una situación en que los factores fuesen remunerados en función de su aportación al proceso de producción, tenía consecuencias económicas negativas sobre el ciclo económico, puesto que las rentas de menor propensión marginal al consumo aumentaban su participación en el producto y porque, además, se producían unas consecuencias sociales indeseables por la injusta distribución de la renta que acarreaba el proceso. Torres atribuia unos efectos de distorsión equivalentes a la inflación y al aumento del grado de monopolio en los diversos sectores, de forma que el análisis de los efectos del crecimiento económico en la producción y la distribución se convierte en un argumento repetitivo en su pensamiento económico ${ }^{18}$.

Desde el punto de vista de la difusión de las doctrinas económicas, cabe decir que existe un innegable paralelismo con el planteamiento de

${ }_{17}$ He catalogado a lo largo de los escritos de Torres cinco versiones de su modelo macroeconómico y, por tanto, de la ecuación de beneficios (Torres, 1949, 1953-1955). El beneficio «funcional» se corresponde con la renta asignada al empresario por asumir riesgo una vez repartidos salarios $\left(T_{j}, T_{c}\right)$ e interés $\left(K_{i}, K_{c}\right)$. En el procedimiento de agregación empleado por Torres el beneficio "funcional» se corresponde con los excedentes del sector de bienes de consumo, omitiéndose el beneficio del sector de bienes de inversión, pues, siguiendo a Pedersen, se excluyen las transacciones interempresariales. Véase Apéndice 1. A mi juicio, son dos las razones de esta omisión. De una parte, no afecta al resultado final que pretende alcanzar Torres y, sin embargo, su introducción complica excesivamente la demostración. De otra parte, preserva la distinción analítica fundamental empresarios-no empresarios, es decir, los factores de producción que asumen riesgo y los que no lo asumen. Por tanto, el grupo de empresarios queda agrupado y caracterizado como agentes económicos que asumen riesgo.

${ }^{18}$ En la ecuación (5) del Apéndice 2 se observa cómo el aumento de la inversión, o una política anticíclica a través del aumento del déficit fiscal aumentan los precios y, en consecuencia, también el beneficio «funcional». 
Keynes en Treatise on Money (1930). En efecto, tanto en el Treatise como en los trabajos de Torres, el beneficio se trataba como una renta residual. También, de forma análoga al Treatise, tanto precios como beneficios se determinaban por medio de una ecuación -fundamental la denomina Keynes - que hace depender aquéllos de las diferencias entre inversión y ahorro. Sin embargo, Torres enriqueció la ecuación al vincular positivamente precios y beneficios al aumento del grado de monopolio, al déficit público y al saldo de la balanza de pagos (Torres, 1953-1955) ${ }^{19}$. En consecuencia, Torres justificaba la intervención estatal en los términos que expresa la ecuación de los beneficios: tanto la política monetaria como la fiscal o las políticas antimonopolistas pueden contribuir a corregir la distribución de la renta y a promover el crecimiento económico.

Sin duda fueron los escritos de los economistas de la Universidad de Aarhus, el danés Jörgen Pedersen y el alemán Eric Schneider principalmente, quienes marcaron profundamente la pauta seguida por Torres ${ }^{20}$. Estos autores construyeron un modelo macroeconómico que tenía un notable paralelismo con el Treatise de Keynes. Esto explica la particular y a veces sorprendente combinación de conceptos propios de The General Theory (1936) con otros procedentes de o paralelos a los del Treatise on Money (1930), que caracteriza los escritos de Torres de los años cuarenta y cincuenta. Esta «vuelta» al Treatise también se detecta en su teoría monetaria. Torres, siguiendo a Pedersen, diferencia entre medios de pago «ociosos» y «activos, eliminando del vínculo dinero-precios, al igual que el economista danés, los saldos ociosos. Esto no sucedía en el pionero trabajo de Torres Teoria General del Multiplicador (1943), donde la distinción saldos ociosos y saldos activos era un elemento explicativo del ciclo económico, pero no del nivel de precios. También allí la referencia era el Keynes de The General Theory (1936) y el objeto del trabajo la explicación del ciclo

${ }^{19}$ En el Treatise, Keynes (1971 [1930], p. 122) plantea dos ecuaciones fundamentales

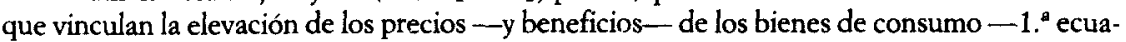
ción fundamental- y de los bienes de inversión - 2. ${ }^{a}$ ecuación fundamental- por encima de los costes de producción, a las diferencias unitarias entre inversión y ahorro. A diferencia de Keynes, Torres construyó tres ecuaciones fundamentales. Las tres vinculaban los precios de los bienes de consumo - y, por tanto, los beneficios- a las diferencias entre inversión y ahorro. Por tanto, de nuevo se omite el razonamiento para los bienes de inversión. Véase Apéndice 2.

${ }^{20}$ En el artículo publicado en la revista Anales de Economía titulado «La relación dinero y precios», el vínculo con el Treatise on Money y la téoría monetaria de Pedersen es aún más evidente. El propio título es tomado de Pedersen, quien utiliza dicha expresión para designar la teoría monetaria (Pedersen, 1945, pp. 157-167). Su obra Teoria y Política del dinero (1945) contribuyó decisivamente a orientar a Torres hacia el Treatise on Money. 
económico y no el estudio de las condiciones de desarrollo de la economía española ${ }^{21}$.

\section{Keynesianismo y política social}

Diagnosticado específicamente el problema, que Torres pensaba era connatural a los procesos de industrialización y explicaba el título y contenido de Teoría de la política social (1949), su solución es inspirada por el Capítulo Xxiv de The General Theory y por parte de la literatura key-

${ }^{21}$ Durante los años treinta, Torres desarrolló su análisis en el marco de una noción genérica, más que de una teoría precisa, de equilibrio general microeconómico en el que existia una interdependencia de precios y cantidades de las distintas mercancías. Esta noción compartía con la teoría walrasiana el papel central asignado a las decisiones maximizadoras de los individuos. Sin embargo, difería del planteamiento walrasiano, tal como anteriormente se ha mencionado, en que la posición de equilibrio alcanzada podía no ser deseable y, por tanto, abría un espacio a la intervención del Estado por medio de la política de precios. La forma genérica en que Torres utiliza esta noción de equilibrio hace poco fructífera la discusión sobre el mecanismo de ajuste de equilibrio - tâtonnement-, o sobre cuestiones que hoy en día son centrales en la moderna teoría del equilibrio general, tales como la existencia, unicidad o estabilidad del equilibrio. En la posguerra, el concepto de equilibrio de Torres adquiere un carácter macroeconómico. Por tanto, los precios relativos microeconómicos no desempeñan ningún papel, y desde el punto de vista monetario la variable relevante es el nivel de precios. En consecuencia, la idea de que las fuerzas del mercado son incapaces de alcanzar una posición de equilibrio microeconómico deseable, se transforma en la idea de que el nivel de output alcanzado por el libre juego de las fuerzas de mercado no es suficiente para que se produzca el pleno empleo. Esto aparece claramente en Teoría General del Multiplicador (1943), trabajo que intenta estudiar los determinantes del nivel de demanda efectiva a lo largo del tiempo, por medio de los determinantes de la inversión y a través de los mecanismos del multiplicador y el acelerador. El planteamiento del equilibrio en Teoria de la Política Social (1949) y, en general, en el Torres de la década de los cincuenta, es decir, el que se ha analizado en este trabajo, sigue manteniendo la idea de que el mercado por sí solo puede no alcanzar el equilibrio. Como muestra la ecuación (5) del Apéndice 2, el equilibrio se produce cuando el precio se iguala al coste de producción - primer término de la ecuación-, y el beneficio, tal como lo definen Keynes en el Treatise on Money (1930) y Torres, se hace nulo. Según ambos, el mercado no puede garantizar la igualdad de ahorro e inversión. Keynes, en 1930, pensaba que la política monetaria era suficiente para restablecer el equilibrio. Torres, como se observa en la ecuación (5), también atribuía un papel estabilizador a la política fiscal, manteniendo, por tanto, una conexión con el Keynes de 1936. Sin embargo, no aparece, ni en el Torres de los años cuarenta ni en el de los cincuenta, el concepto de incertidumbre con la centralidad que lo hace en The General Theory (1936) como elemento esencial del desequilibrio económico. Cabe, por último, decir que, al igual que sostenía Pedersen, Torres preserva la soberanía individual de los agentes económicos y el propio mecanismo de arbitraje del mercado, que constituyen una parte central de su núcleo metodológico (Olesen, 2001, Zabalza, 1998). El concepto de equilibrio en Keynes puede consultarse en Caravale (1992). El debate en torno a las mutaciones de dicho concepto de equilibrio en Keynes entre 1930 y 1936, en Marcuzzo (1998) y Renaud (1997). 
nesiana posterior. Torres estimaba que la nueva estructura del Estado «intervencionista» permitía introducir políticas anticíclicas redistributivas con el fin de reducir los efectos socialmente disgregadores del desarrollo industrial. El objetivo primordial era fomentar el crecimiento económico reconciliándolo con la justicia distributiva. Por tanto, la Teoría de la política social (1949) culmina una reflexión que vertebra todo su pensamiento económico durante la postguerra: el estudio del desarrollo económico y sus consecuencias en el marco de una economía atrasada y con gran peso del sector agrícola. Una preocupación común a muchos de los reformadores y economistas de la España contemporánea, pero que Torres afronta con un instrumental teórico y una visión social novedosos.

¿Pero cuáles eran concretamente estas políticas redistributivas? $\mathrm{La}$ segunda parte - «parte especial»- de la Teoría de la política social (1949) se propone precisar la política social que permitiera compatibilizar ambos objetivos, el «social» y el «económico». Con este fin, Torres catalogó y analizó exhaustivamente los efectos «impacto» y «secundarios» de las más importantes políticas sociales: política de salarios, participación de beneficios, seguros sociales y política de servicios sociales. El resultado fue una inequívoca opción por una política de redistribución que se implementaría por medio de un impuesto progresivo sobre la renta y por la consiguiente prestación de servicios sociales, frente a las otras tres alternativas que se acaban de mencionar. De una parte, los efectos «secundarios» de las políticas de elevación de salarios y participación en los beneficios neutralizan los favorables efectos «impacto» debidos al proceso inflacionista que desencadenan tales medidas ${ }^{22}$. Por otra, los seguros sociales, según Torres, están limitados técnicamente al restringir su cobertura a los riesgos estimables por la ciencia actuarial, excluyendo los imprevisibles, tales como la enfermedad o el paro. Es significativo que este planteamiento se distanciaba del expresado por Beveridge en Full Employment in a Free Society, que, no obstante, fue positivamente acogido en los círculos y publicaciones -Nueva Economía Nacional - cercanos a Falange ${ }^{23}$. Los servicios sociales,

${ }^{22}$ Torres (1949, pp. 151-211). Suponia, por tanto, un reconocimiento de la inelasticidad tanto de la oferta agraria como industrial españolas, pues el aumento de la demanda monetaria causada por el aumento salanal o el aumento de la participación en los beneficios, no se correspondía, debido a los problemas característicos de la producción agraria y, especialmente, a los embotellamientos productivos de los sectores industriales, con un aumento de la oferta productiva.

${ }^{23}$ Véase, por ejemplo, Gay (1946), Girón de Velasco (1945), Nueva Economía Nacional $(1946,1946 a)$. El contenido del programa de medidas propuesto por Beveridge «one planned outlay on a long-term programme» se puede leer en los párrafos 213 a 222 (pp. 159-166) 
por el contrario, se ajustan a las prescripciones derivadas de la discusión teórica de la Teoría de la Política Social (1949). Por una parte, según Torres, poseen la estimable ventaja de que su financiación puede realizarse por medio del presupuesto, permitiendo su integración en el conjunto de la política económica de acuerdo al principio de «unidad de caja». Como la mayoría de estos servicios sociales se satisfacen con bienes producidos por las industrias de bienes de consumo, se modificaba la estructura de la producción y, en consecuencia, se reducía el beneficio desvinculado del riesgo ${ }^{24}$. Por otra parte, la financiación de los servicios sociales por medio de un impuesto personal también se ajusta a las prescripciones que se derivan de la discusión teórica de la Teoría de la política social (1949). En efecto, por un lado, se trata de una exacción personal y, por tanto, se evita toda interferencia en el proceso de distribución «funcional» de la renta, al no recaer el impuesto sobre los costes de producción. Por otro, cumple la exigencia de la progresividad en la tributación, cuyo fundamento no reside en el principio microeconómico de la utilidad marginal decreciente del ingreso, como ocurría en el lejano Studi sull'imposta di succesione escrito por Torres en 1927, sino sobre el mecanismo keynesiano de la propensión a consumir.

Hasta aquí la interpretación que se sostiene en este trabajo. Sin embargo, son reconocibles ciertas incoherencias en el planteamiento de Torres, algunas de ellas denunciadas por Knox en la recensión de Teoría de la politica social publicada en The Economic Journal (Knox, 1950). Quizás, la más seria sea la definición de la distribución de la renta en términos «funcionales» y no personales. Una distribución injusta, a juicio de Torres, se caracteriza por una mayor participación de los beneficios en el total de la renta a costa de los salarios y las rentas del capital, sin que los empresarios asuman un riesgo mayor; pero, en realidad, la distribución «funcional» de la renta no es un indicador de la distribución de ésta entre

de Full Employment in a Free Society (1945). Harrod, ya en 1943, se refería, claro está, al primer informe Beveridge de 1942 Allied Services, señalaba las ventajas que supondría situar el denominado seguro de desempleo fuera del esquema Beveridge, por la dificultad que suponía tratar el desempleo como objeto de los métodos actuariales (Harrod 1943).

${ }^{24}$ Fisher (1946). Por la misma época, y en referencia al sistema contributivo que planteaba Beveridge, una de las máximas autoridades en esta materia señalaba que no existían razones para suponer que la Seguridad Social que se financia por medio de aportaciones fuera superior a un sistema financiado por imposición general (Peacock, 1952, pp. 103-104). Según Peacock, la financiación por medio de los impuestos permite establecer unas contribuciones de acuerdo con el ingreso e integrar la Seguridad Social en el conjunto de la política del gobierno. 
los agentes económicos. El juicio sobre los cambios en la distribución de la renta debe definirse en términos personales, es decir, una vez distribuidas las rentas factoriales - los beneficios, los salarios y las rentas derivadas de la propiedad del capital - entre los agentes económicos que tienen derecho a percibirlas de acuerdo a su contribución al proceso productivo - los empresarios que asumen riesgo, los trabajadores y los propietarios de dichos factores-. Otra objeción de cierta entidad es la parcial interpretación del Capítulo xxrv de The General Theory (1936) de Keynes. Éste, como harán después otros keynesianos, no sólo identificaba el objetivo del pleno empleo con el objetivo de redistribución de la renta, sino también con la redistribución de la riqueza. Por tanto, estos economistas tuvieron especial interés en reducir las rentas procedentes de la propiedad de los factores y, en particular, las procedentes de la propiedad del capital, por medio de medidas tales como la reducción de la concentración de capital, los bajos tipos de interés y la provisión de oportunidades iguales de educación (Barna, 1945). Torres, por el contrario, ignora estas medidas, con la salvedad de la política antimonopolios y los impuestos de sucesiones y patrimonio. En realidad, su propia trayectoria intelectual revela una oposición explícita a la redistribución de la propiedad, idea en la que confluyen tanto su análisis teórico, al rechazar la redistribución «funcional», como sus creencias agrarias y católico-sociales, manifestadas claramente en el debate sobre la reforma agraria en los años treinta.

Estas debilidades de su planteamiento responden a una lógica precisa. En efecto, Torres se propone destacar los perjuicios derivados de una situación en la que el riesgo se desvincula del beneficio. En este contexto, el indicador más apropiado de la distribución de la renta es el beneficio «funcional» y las políticas de redistribución de la riqueza no son el medio adecuado para redistribuir este beneficio «funcional» excedente en forma de salarios o rentas del capital. En parte, ello explica su preferencia por los autores escandinavos del grupo de Aarhus - Philip, Schneider y principalmente Pedersen - respecto al modelo IS-LM o sus derivados ${ }^{25}$. Precisamente, Teoría y política del dinero (1945) de Jörgen Pedersen, con el que se formaron a iniciativa de Torres varias generaciones de economistas

${ }^{25}$ El modelo IS-LM (LL en la denominación original de Hicks), es la expresión gráfica de lo que se denomina «síntesis neoclásica», que intentaba interpretar la teoría de Keynes en términos de equilibrio económico y como una teoría particular -caso del desempleo en el mercado del trabajo- de una teoria más general. En Darity y Young (1995) se explica la evolución del modelo desde su primera formulación por Hicks, el mismo 1936, y su importancia como punto de referencia de los debates económicos a lo largo de varias décadas. 
españoles, se fundamenta sobre un modelo de distribución que vincula riesgo y beneficio. Por el contrario, las sucesivas versiones de lo que finalmente se denominó modelo IS-LM o síntesis neoclásica, dominante entre los economistas keynesianos desde la década de los cuarenta hasta finales de los sesenta, ignoran este vínculo y los cambios en la distribución. En consecuencia, el modelo de Pedersen se adecuaba al problema específico de la industrialización de España y a la particular percepción del mismo por Torres.

\section{UN ANÁLISIS KEYNESIANO DE LA ECONOMÍA ESPAÑOLA EN LOS AÑOS CINCUENTA}

Algunos autores han destacado el carácter «ingenieril» que inspiraba la política de industrialización llevada a cabo por el régimen franquista durante los años del ajslamiento, ignorando cualquier tipo de racionalidad económica y entregándose al objetivo dominante de la autarquía económica ${ }^{26}$. Los «teóricos» que la inspiraban, como Antonio Robert, Manuel Fuentes Irurozqui o Higinio Paris Eguilaz, utilizando como fuentes doctrinales al rumano Manoilescu o las más lejanas de List o Carey, promovieron una política de sustitución de importaciones con el fin de convertir a España en una potencia industrial ${ }^{27}$. Paralelamente y al igual que ocurría con los teóricos del corporativismo italiano y del nacionalsocialismo alemán, se detecta en éstos y otros autores vinculados a Falange una identificación de la política social con la elevación salarial. Esta política fue llevada a la práctica de manera poco afortunada desde el Ministerio de Trabajo por José Girón de Velasco a partir de 1956, agudizando la tendencia inflacionista de la economía española, que obligó finalmente a la estabilización de agosto de 1959. Compañera de viaje de la política de elevación salarial fue la instauración de un sistema de seguros sociales que habían comenzado a implantar las autoridades franquistas ya desde 1938, en plena Guerra Civil (Comín, 1996). En realidad, ello respondía al ideario falangista predominante en el Ministerio de Trabajo. Se apoyaba teóricamente sobre la idea de que tanto la elevación de los salarios como la limitación de los beneficios impedían la repercusión de las fases del ciclo económico sobre los trabajadores, evitando los efectos sociales derivados de la ines-

${ }^{26}$ Véase González (1979), Velasco (1984).

27 Fuentes Irurozqui (1942), Manoilescu (1943), Paris Eguilaz (1945), Robert (1943). 
tabilidad económica y resolviendo, en consecuencia, la «cuestión social» ${ }^{28}$. Durante la década de los cincuenta, Torres manifestó públicamente sus dudas sobre la viabilidad de dichas políticas. A lo largo de múltiples conferencias celebradas en los más diversos foros y recogidas en gran parte en los volúmenes Teoria y práctica en la política económica (1955) y Juicio de la actual política económica española (1956), trató de persuadir a las autoridades económicas de la imperiosa necesidad de eliminar las irracionalidades en que incurría la política económica.

La denuncia de Torres, al igual que las iniciativas que emprendió, tuvieron como referencia su reflexión teórica de los años cuarenta. Estas iniciativas tomaron en esencia dos direcciones. De una parte, la defensa de la tributación personal por medio de un impuesto personal progresivo sobre la renta (Torres, 1955). De otra, la necesidad de la coordinación de las distintas parcelas de la política económica y en particular del desarrollo de los diversos sectores productivos, que se fundamentaba en la idea de raíz keynesiana de la negación de la existencia de un mecanismo coordinador autónomo del mercado. Mientras una se implementaría desde el Ministerio de Hacienda, la otra exigiría la creación de un organismo coordinador -la Oficina para la Coordinación y Planificación Económica (OCYPE) - . Torres estuvo plenamente implicado en la fundación de la OCYPE inspirándose en el plan holandés, modelo que Torres adoptó siguiendo el camino marcado por la economista italiana Vera Cao-Pinna ${ }^{29}$. En ambos casos trató de encauzar su influencia por medio de las posibilidades que ofrecían la llegada de ministros de mentalidad algo más abierta, tales como Francisco Gómez Llanos y Mariano Navarro Rubio, con quienes Torres colaboró estrechamente.

\section{La personalización de la tributación}

En diciembre de 1932, el Parlamento republicano aprobó la Ley Carner que trataba de introducir el principio de personalidad en la tributación española. Manuel de Torres se había significado por su oposición a la ley. Por una parte, siguiendo a Luigi Einaudi rechazaba la obligatoriedad de la declaración, pues, a su juicio, suponía la intromisión en la intimidad

${ }^{28}$ Girón de Velasco (1945), Paris Eguilaz (1938, pp. 117-131).

29 Según la interpretación más extendida, López Rodó, apropiándose de la idea de Torres, adoptó el sistema francés de planificación indicativa (Cotorruelo, 1976; González, 1978). 
de los ciudadanos. Por otra, denunciaba las nefastas consecuencias que la imposición personal acarrearía sobre el desarrollo económico al gravar doblemente la renta ahorrada respecto a la consumida ${ }^{30}$. Este último argumento se apoyaba sobre una teoría del desarrollo económico, anteriormente mencionada, que situaba el ahorro como la variable de la que dependía la inversión. Sin embargo, su reflexión teórica a lo largo de la década de los cuarenta modifica profundamente su pensamiento hacendístico, abierto ahora a la introducción de la personalización y la progresividad. Torres, de acuerdo con las orientaciones de la Hacienda pública keynesiana, asumió el principio de «beligerancia», de tal manera que la política financiera no debía asumir fines propios -el equilibrio presupuestario, por ejemplo-, sino que se integraba en el conjunto de la política económica y se convertía en su principal instrumento.

En este nuevo contexto teórico se sitúa el ofrecimiento y la posterior colaboración de la Facultad de Ciencias Políticas, Económicas y Comerciales con el Ministerio de Hacienda tras la llegada de Francisco Gómez Llanos. La colaboración se institucionalizó con la creación de la «Comisión de la Contribución sobre la Renta», uno de cuyos frutos fueron las «Enmiendas del profesor Torres al Anteproyecto de Ley Articulada de mayo de 1954» ${ }^{31}$. Torres planteaba la introducción de la imposición personal en el sistema tributario español, que, a su juicio, no respondía únicamente a los principios de justicia y equidad tributarias, sino también al «principio de eficiencia económica» del impuesto (Torres, 1969). Es decir, el impuesto personal progresivo era un instrumento anticíclico fundamental de la política económica y un medio de atenuar las consecuencias sociales negativas de la industrialización.

\section{La coordinación de la política económica}

La idea de «coordinación de la política económica» tuvo como frutos tardíos la Contabilidad Nacional, la mencionada OCYPE e impulsó a

${ }^{30}$ Indudablemente, ambas ideas tenían sus raíces en las tesis de Luigi Einaudi. Durante la década de los treinta y cuarenta, el debate en torno al doble gravamen del ahorro en los sistemas de imposición personal fue una de las cuestiones más discutidas entre los economistas que abordaban las cuestiones relativas a la Hacienda Pública.

${ }^{31} \mathrm{La}$ colaboración de la Facultad se materializó en tres aportaciones: el llamado «Informe Comisión Torres», que bajo la dirección de Torres - aunque éste apenas participarafue elaborado por César Albiñana, Enrique Fuentes Quintana y Juan Velarde (Albiñana, 1969). El «Dictamen del profesor Torres» (Torres, 1969) y «Enmiendas del Profesor Torres al Anteproyecto» (Torres, 1969a), sin embargo, son propiamente de Torres. 
Torres a sumarse a la empresa de la elaboración de las Tablas Input-output ${ }^{32}$. El «Epílogo» de las Tablas Input-output de 1954 (TIOE-54, 1958), cuya autoría corresponde a Torres, expresa su preocupación explícita por el desarrollo económico y destaca las posibilidades que ofrecen las Tablas Input-output como instrumento de la programación económica en el contexto de una economía como la española de los años cincuenta. En efecto, en este «Epílogo» Torres identifica de forma cuantitativamente más rigurosa el problema fundamental de los embotellamientos productivos en los sectores industriales; es decir, la denominada tendencia autofágica de algunas producciones industriales -industrias químicas, mecánicas, eléctricas y textiles- cuyo desarrollo generaba nuevas necesidades de importación de minerales y materias primas (Torres, 1958).

Pretendía también el «Epílogo» la demostración de la dependencia exterior de la economía española con el fin de aportar argumentos a favor de la apertura y en contra de la tesis de la «autarquía» que inspiró la «industrialización a ultranza» hasta bien entrados los años cincuenta ${ }^{33}$. Finalmente, Torres utilizó los datos de las TIOE-54 para demostrar que una estrategia de promoción de las exportaciones era una vía más eficiente que la sustitución de importaciones. Con este fin, simplificando un procedimiento empleado por Cao-Pinna, Torres clasificó los sectores económicos en «exportadores» e «importadores», calculando seguidamente lo

${ }^{32}$ Las Tablas Input-output de 1954, primeras de la economía española, se debieron a la iniciativa de Valentín Andrés Álvarez desde el Instituto de Estudios Políticos y fue elaborada por un equipo formado por Alcaide Inchausti, Begué, Fernández Castañeda y Santos Blanco, al que se sumó Torres cuando los trabajos estaban a punto de finalizar. Torres se limitó a facilitar su publicación y escribir el «Epílogo» (Sánchez Hormigo, 1991, pp. 162-170; Torres, 1958). No obstante, por medio de Torres se contactó con Vera Cao-Pinna y ello tuvo gran relevancia por dos motivos: la notoriedad que la profesora sarda habia adquirido tras el éxito de un seminario internacional sobre los aspectos teóricos y prácticos del modelo de Leontieff, y porque permitió la utilización del ordenador del Instituto de Cálculo de Roma para calcular la matriz inversa de 29 filas y 29 columnas. Cao-Pinna se desplazó a Madrid y explicó el método del análisis Input-output en la Facultad de Ciencias Políticas y Económicas. Allí compartió despacho con Leontieff, también de visita por España. El concurso de Cao-Pinna fue de gran utilidad por la similitud de la estructura económica de España e Italia. De hecho, la primera aplicación de las TIOE-54 corrió a cargo de la propia Cao-Pinna, quien comparó los resultados de las tablas españolas con las equivalentes italianas (Fornengo, 1997, pp. 161-162; Cao-Pinna, 1958, pp. 23-112).

${ }^{33}$ Tanto la generación de un clima aperturista desde los ministerios de Hacienda, Comercio y Asuntos Exteriores, como las resistencias a la liberalización en los años previos a la estabilización se relatan en González (1979, pp. 158-163). Guirao sostiene, no obstante, que en ocasiones la política comercial no asumía únicamente el objetivo de la autarquía, sino también de la modernización, como parece deducirse del Plan de Exportaciones de 1944 (Guirao, 1998). 
que llamaba productividad sectorial por medio del cociente entre valor añadido por el sector en cuestión y el output total; de este modo, construía una medida de la capacidad de generación de renta de cada uno de los sectores. Los datos de las TIOE-54 revelaban la superioridad, según la medida de Torres, de los sectores calificados como «exportadores», en cuanto éstos tenían una mayor capacidad de generación de divisas ${ }^{34}$. En definitiva, la utilización de las TIOE-54 corroboraba la estrategia de industrialización «racional» que Torres defendía desde la década de los cuarenta. La agricultura de exportación posibilitaría la eliminación de los estrangulamientos de la actividad industrial por medio de la aportación de las divisas que desbloquearían los procesos productivos industriales. El requisito de todo ello era la apertura hacia el exterior y el fin de la autarquía. De nuevo, los problemas del desarrollo económico se traducían en el caso español y en la interpretación de Torres, en términos de una nueva relación agricultura-industria.

Las TIOE-54 tuvieron su continuidad en las Tablas Input-output 1954-1957, proyecto mucho más ambicioso y dirigido en esta ocasión por el propio Torres, autor de su «Prólogo» (Torres, 1960). Según Ángel Alcaide, este «Prólogo» es la aportación «más práctica y trascendental» de la obra porque «encierra la esencia de toda orientación para el planeamiento del desarrollo económico» (Alcaide, 1970). En realidad, esto no era una novedad en el pensamiento de Torres, pues se trataba de nuevo del problema de los estrangulamientos productivos y sus posibles soluciones. No obstante, en cierto modo el «Prólogo» es simbólico al escribirse en 1959, en un momento crucial para la economía española. Es ilustrativa la pregunta allí planteada: «cy después de la estabilización qué?», aludiendo al carácter estructural de los estrangulamientos productivos, cuya eliminación exigía la programación económica por medio de la información ofrecida por las Tablas Input-output ${ }^{35}$.

Poco tiempo después, en 1960, guiado por esta necesidad de aportar instrumentos cuantitativos a la programación económica, Torres presentó, en un importante Congreso internacional celebrado en Bellagio, un conjunto de análisis originales que pensaba adecuados para los países en vías de desarrollo y que había aplicado en España. Entre ellos destacan el análisis temporal de los costes medios y marginales y las balanzas intersectoriales que fueron muy bien acogidos entre algunos autores internacionalmente

34 Torres (1958, pp. 118 y 131-132), Cao-Pinna (1956, pp. 229-245).

35 Véase Torres (1947) y Castañeda (1958) para evitar confusiones acerca del contenido de la expresión programación y planificación económicas. 
reconocidos en la materia que se encontraban allí presentes (Isard y Cumberland, 1960) ${ }^{36}$. El esfuerzo mereció la pena y las aplicaciones inmediatas de las Tablas Input-output - - en particular, las TIOE-54 - fueron fructíferas y en línea con las preocupaciones que Torres expresaba. La primera fue el cálculo de la repercusión de las tarifas ferroviarias sobre el coste de las mercancías (Torres, 1958). La segunda, a instancias de la FAO, trataba de determinar el grado de desarrollo del sector agrícola compatible con el desarrollo industrial (ICE, 1959). También se utilizaron las TIOE-54 para diseñar el Plan Nacional de Inversiones de 1959, cuya distribución trataba de fomentar el desarrollo de los sectores agrícolas netamente «exportadores», tal como Torres los había definido (OCYPE, 1959). Por último, las Tablas Input-output constituyeron la base del influyente trabajo encargado por el Ministerio de Comercio, también dirigido por Torres, «El comercio exterior y el desarrollo de la economía española», cuyos resultados se resumen en las siguientes palabras:

«cuando consideramos la totalidad de la balanza del país, vemos que es posible incrementar la producción de estos sectores, sin gravar la balanza de pagos, en tanto en cuanto desarrollemos las exportaciones de los sectores absolutamente exportadores. En otros términos, que la condición para el desarrollo industrial del país es, salvo el caso de aportación de capital exterior, el incremento de las exportaciones que anteriormente hemos definido como procedentes de sectores exportadores por su propia naturaleza» (ICE, 1959).

La iniciativa de la primera Contabilidad Nacional se sitúa en la misma línea. Torres había manifestado la complementariedad de las Tablas Input-output y la Contabilidad Nacional con el objeto de coordinar la política económica en su conjunto, tal como argumentaban los especialistas de la época (Stone, 1954). Mientras las primeras eran el instrumento para determinar el «plan de producción» de la economía, la segunda se encaminaba a diseñar el «plan monetario» (Torres, 1956). Velarde destacaba

${ }^{36}$ Las balanzas sectoriales definidas para el comercio internacional e interregional permitían determinar con criterios más rigurosos si un sector era exportador - Totally Exporting Sector- o importador - Totally Importing Sector-, al incluir no solamente los movimientos de outputs, sino también de inputs, tanto directa como indirectamente (Torres y Lasuen, 1960). Los costes medios - cociente entre los inputs de un determinado sector y su output para cada uno de los años-y marginales - cocienté entre el aumento de inputs respecto al año y el aumento del output también para cada año- definidos para una sucesión de años permitían determinar cuáles eran los sectores - ya fueran exportadores, ya importadores- que a lo largo del tiempo mejoraban sus estructuras de costes. Los autores concluían que eran los sectores exportadores. 
las cualidades de Torres para llevar a término un proyecto de tal envergadura: decano de la Facultad, director del Instituto Sancho de Moncada, la disposición de una ayuda que consiguió gracias a sus buenas relaciones en el Ministerio de Hacienda y la dirección de un equipo que había ya trabajado conjuntamente en la elaboración de la 'TIOE-54 (Velarde, 1978). Habria que añadir su notable experiencia acumulada en el cálculo de las series de Renta Nacional, precedente de la Contabilidad Nacional, en el seno del Consejo Nacional de Economía. Desde entonces ya era manifiesto el propósito práctico de la investigación, como revelan las discusiones en el seno de la Comisión de la Renta de 1945. A diferencia de Zumalacárregui y Perpiñá Grau que defendían limitar la discusión al mero cálculo técnico, Torres pretendía extraer consideraciones específicas de política económica (Martínez Mesa, 1997).

\section{A MODO DE CONCLUSIÓN: EL PODER DE PERSUASIÓN DE LAS IDEAS ECONÓMICAS}

En El problema triguero y otras cuestiones fundamentales de la agricultura española (1944) Torres reconocía que, al igual que Flores de Lemus, había cometido un error de interpretación al omitir la demanda efectiva como factor explicativo de la inflación en España durante la Gran Guerra (Torres, 1944). Fue lo que denominaba «moderna teoría» la piedra de toque que le permitió desvelar su error analítico. Desde este punto de vista, este trabajo trata de reivindicar para las ideas un cierto poder autónomo de persuasión, capaz de sustituir a otras ideas y de transformar la percepción de la realidad, algo especialmente pronunciado en la doctrina keynesiana (Hall, 1989). Sin duda, la sucesión de acontecimientos que desde el lejano período republicano se produjeron tanto en el ámbito de los hechos como de las ideas económicas modificaron sustancialmente el pensamiento económico de Manuel de Torres. Al retomar la pluma ya bien entrados los años cuarenta, reaparece un economista «moderno», que ha asimilado de una forma singular las profundas transformaciones que experimentó la ciencia económica a lo largo de las décadas de los treinta y cuarenta. El agrocentrismo que caracterizaba su concepción del desarrollo económico de España en el período republicano es sustituido durante la posguerra por una estrategia de industrialismo racional, que exigía su coordinación con el sector agrario cuya contribución al proceso era imprescindible en las primeras etapas de la industrialización. Este aspecto fundamental del pen- 
samiento económico de Torres ha pasado prácticamente inadvertido en los trabajos precedentes. Sin pretender realizar una reconstrucción racional de este proceso de evolución intelectual, el trabajo ha desvelado algunas de las claves que permiten establecer el sendero de dicho itinerario intelectual; es decir, un conjunto de elementos comunes a las dos etapas que, sin embargo, adoptan forma diferente.

Sin duda, uno de ellos es la creencia en la inestabilidad que el laissez-faire introducía en el sistema económico, al ser incapaz de alcanzar por sí mismo una posición de equilibrio en todos los mercados. Aunque en los comienzos de su formación Torres recibió una poderosa influencia del economista liberal italiano Luigi Einaudi, pronto expresó serias dudas sobre la capacidad del sistema económico liberal para superar la crisis económica. De forma peculiar participó del sentimiento de decepción con la doctrina liberal que Hirschman considera fundamental para generar un estado de opinión favorable a una mayor intervención del Estado en la economía (Hirschman, 1997). Desde entonces inició una búsqueda intelectual que le llevaría a indagar durante los años treinta en los teóricos italianos del corporativismo. Pero no era la estructura del sistema de corporaciones en sí mismo - a su juicio éste era imposible de acoplar a la realidad económica española-, sino el carácter intervencionista de la doctrina el que atrajo la atención de Torres. De hecho, fueron los economistas de la versión moderada del corporativismo italiano denominada «tercera vía», como Barone o Serpieri, para quienes la estructura corporativa era un elemento accidental del sistema, los que inspiraron el intervencionismo económico de Torres. Tras la Guerra Civil española, Torres se encontró con el avance inicial del keynesianismo que creó nuevos espacios anteriormente inexistentes en el terreno del intervencionismo estatal, estableciendo unos nuevos límites y relaciones entre la esfera económica privada y pública (Hirschman, 1997).

El vínculo riesgo-beneficio, elemento fundamental de la teoría de la distribución de Torres, también toma ahora un nuevo perfil. Durante los primeros años treinta, este vínculo se manifiesta en el papel central de la aparcería como modalidad productiva en su modelo de desarrollo económico. En la posguerra, este vínculo conduce a Torres a asimilar la teoría de la distribución macroeconómica de la rénta característica del grupo de economistas de Aarhus. La similitud de los planteamientos de Pedersen y Schneider con los de Keynes en su principal obra monetaria aboca al propio Torres a una posición cercana al Treatise on Money (1930). Es decir, 
a un planteamiento que se aleja del modelo IS-LM ampliado, la versión del keynesianismo dominante en los debates macroeconómicos durante la posguerra en el ámbito anglosajón.

El trabajo también ha mostrado una característica singular de Torres en el panorama del pensamiento económico de la posguerra en España que heredarían sus discípulos: el nexo entre la reflexión teórica, el análisis de las específicas posibilidades de desarrollo de la economía española y la tenaz tarea persuasiva dirigida a las autoridades económicas. En esta línea se sitúa la interpretación de la teoría keynesiana en términos de política económica y la construcción de un modelo, agregando conceptos y procedimientos de otros economistas que, pese a algunas carencias analíticas, se adaptaba a las exigencias de la realidad económica y política españolas. De una parte, desde el punto de vista de la «vision», era compatible con el sistema político franquista, pues no cuestionaba los objetivos políticos y económicos del régimen, aunque reivindicaba para el economista un margen de actuación en el ámbito de los medios y de la compatibilidad de los fines. De otra, el modelo se adaptaba al principal problema de la economía española, el desarrollo económico a través de la industrialización y sus efectos directos e indirectos sobre los distintos sectores sociales. Naturalmente, el modelo IS-LM, a diferencia del modelo Pedersen-Schneider, más adecuado para el estudio de la estabilidad cíclica, no respondía a estas exigencias.

Por último, cabe decir que este itinerario recorrido por Torres no es una excepción en el panorama de la difusión de las ideas keynesianas en los países del sur de Europa, incluido España (Almenar, 2002). Por ejemplo, los economistas anteriormente mencionados de la «tercera vía» como Amoroso, Del Vecchio o De Stefani, que sostenían una intervención estatal sin negar algunos de los fundamentos de la economía neoclásica como el «homo oeconomicus» egoísta, el razonamiento marginalista o el respeto a la propiedad privada, encuentran una continuidad en la parte de la doctrina keynesiana crítica con el sistema del laissez-faire. Esta evolución, era contemplada a posteriori por los propios corporativistas como un proceso natural y previsible. En Portugal, el keynesianismo, sin embargo, fue utilizado por algunos economistas vinculados al régimen salazariano, éste es el caso de Correia, con el fin de justificar una estrategia de desarrollo industrial ${ }^{37}$.

${ }^{37}$ Bastien (2002), Bastien y Cardoso (1998), De Cecco (1989), AAVV (1984). 


\section{APÉNDICE 1}

El diagrama de flujo circular (Torres, 1949, p. 45)

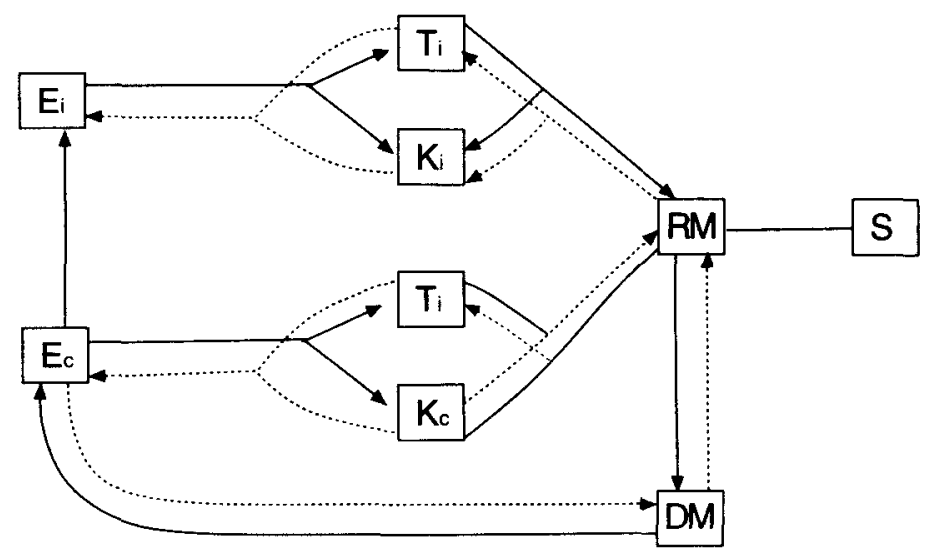

$\mathrm{E}_{\mathrm{i}}$ : grupo de empresarios productores de bienes de inversión.

$\mathrm{E}_{\mathrm{c}}$ : grupo de empresarios productores de bienes de consumo.

$\mathrm{T}_{\mathrm{i}}$ : rentas percibidas por los trabajadores del sector de los bienes de inversión por su trabajo.

$\mathrm{T}_{c}$ : rentas percibidas por los trabajadores del sector de los bienes de consumo por su trabajo.

$\mathrm{K}_{i}$ : rentas del grupo de capitalistas de las industrias de bienes de inversión.

$\mathrm{K}_{\mathrm{c}}$ : rentas del grupo de capitalistas de las industrias de bienes de consumo.

RM: Renta Monetaria.

DM: Demanda Monetaria.

S: ahorro.

........ corriente real.

corriente monetaria.

La deducción del beneficio de Torres de acuerdo al flujo circular es la siguiente:

Beneficio $=$ Ingresos - Coste de Producción $=(R M-S)-$ $-\left(\mathrm{T}_{\mathrm{c}}+\mathrm{K}_{\mathrm{c}}\right)=\left(\mathrm{T}_{\mathrm{i}}+\mathrm{K}_{\mathrm{i}}+\mathrm{T}_{\mathrm{c}}+\mathrm{K}_{\mathrm{c}}\right)-\mathrm{S}-\left(\mathrm{T}_{\mathrm{c}}-\mathrm{K}_{\mathrm{c}}\right)=\mathrm{T}_{\mathrm{i}}+\mathrm{K}_{\mathrm{i}}-\mathrm{S}=$ $=\mathrm{I}-\mathrm{S}$.

Al igual que Pedersen, Torres excluye loś ingresos y los gastos $\left(T_{i}+K_{i}\right)$ correspondientes al sector de bienes de inversión de la ecuación del beneficio. Por tanto, los beneficios de las empresas de bienes de inversión no se reflejan en la ecuación, pues «consideradas en su totalidad, en las tran- 
sacciones de empresa a empresa, lo que es beneficio para un grupo es pérdida para otro» (Pedersen, 1945).

\section{Apéndice 2. Las ecuaciones fundamentales de Torres}

(Torres, 1949, 1953-1955)

El punto de partida de Torres es la que denomina ecuación Lindahl-Keynes (Torres, 1949):

$$
Y-S=P_{c} Q_{c}
$$

Y: renta.

$\mathrm{P}_{\mathrm{c}}$ : nivel de precios de los bienes de consumo.

$\mathrm{Q}_{\mathrm{c}}$ : output sector bienes de consumo.

S: ahorro.

De acuerdo a la terminología del flujo circular $\left(Y=T_{i}+K_{i}+T_{c}+K_{c}\right)$. Esta expresión se puede descomponer en $\left(Y_{i}=T_{i}+K_{i}=I\right)$ y $\left(Y_{c}=T_{c}+K_{c}\right)$. Sustituyendo en (2), se llega a:

$$
Y_{i}+Y_{c}-S=P_{c} Q_{c}
$$

Que, convenientemente transformada, es la «primera de nuestras ecuaciones fundamentales»:

$$
P_{c}=\frac{Y_{c}}{Q_{c}}+\frac{I-S}{Q_{c}}
$$

La tercera ecuación fundamental de Torres — la segunda se obvia(Torres, 1953-1955):

$$
P_{c}=\frac{t_{c}}{E}+\frac{I+D+R-S}{Q_{c}}
$$

$t_{c}$ : coste monetario por unidad de factor de producción.

E: productividad o eficacia media de los factores.

$\mathrm{D}$ : déficit fiscal.

R: saldo de balanza de pagos. 
La primera ecuación fundamental del Treatise on Money (1930):

$$
P=\frac{W}{e}+\frac{I^{\prime}-S}{R}
$$

P: nivel de los precios de bienes de consumo.

W: coste monetario por unidad de factor.

E: «coeficiente de eficiencia» que es un indice de productividad global.

I': renta percibida por los factores que han producido los bienes de inversión.

R: output del sector de bienes de consumo.

\section{BIBLIOGRAFÍA}

AAVV (1984): Keynes in Italia: atti del Convegno organizzato dalla Facolta di economia e commercio dell'Università degli studi di Firenze: 4.5 giugno 1983, Milano, Annali dell'economia Italiana-Istituto IPSOA.

Abraham-FroIs, Gilbert; LaRBRE, Françoise (1997): «Le Keynésianisme et sa diffusion en France. Retard ou spécifité de l'accueil français», The 1997 ESHET Annual Conference, Marseille, 27 Fevrier-2 Mars.

Albiñana, César (1969): «La Contribución General sobre la Renta en los años 1953-1954», Madrid, separata de la Revista de Economía Política, núm. 51, enero-agosto de 1969.

AlCAIDE InCHAusti, Ángel (1970): Análisis Input-output, Madrid, Guadiana de Publicaciones.

Almenar, Salvador (1983): «Keynesianos en España (1936-1953)», Debats, 6, pp. 103-108.

- (1997): «Keynesianism in Spain before the "General Theory". "Anticipations" and parallels: Theory and Policies» (mimeografiado), The 1997 ESHET Annual Conference, Marseille, 27 Fevrier-2 Mars.

- (1999): «Keynes's Economic Ideas in Spain before the "General Theory": Spread, "Anticipations" and Parallels», en Luigi PASINETTI, Bertram SCHEFOLD (ed.) (1999), pp. 99-117.

- (2001): «La recepción e influencia de Keynes y del keynesianismo en España (I)», en Enrique Fuentes Quintana (dir.), Economía y economistas españoles, vol. VI, La modernización de los estudios de economia, Galaxia Gutenberg-Círculo de Lectores, pp. 783-851.

- (2002): «La recepción e influencia de Keynes y del keynesianismo en España (II): después de la Teoría General», en Enrique Fuentes QuinTana (dir.), Economía y economistas españoles, vol. VII, La consolidación de los estudios académicos, Galaxia Gutenberg-Círculo de Lectores. 
Almodóvar, Antonio, y Cardoso, José Luis (1998): A History of Portuguese Economic Thought, London, Routledge.

ANDERSEN, P. Nyboe (1946): La política económica en el clearing internacional, Madrid, Aguilar.

BARNA, Tibor (1945): The Redistribution of Incomes Through Public Finance in 1937, Oxford, Clarendon Press.

BASTIEN, Carlos (2002): «Economistas espanhóis no processo de modernizaçao das ideas económicas em Portugal (1945-1959)», en Boletim de Ciencias Económicas, XVL-A, pp. 217-241.

Bastien, Carlos, y Cardoso, José Luis (1997): «The reception of the "General Theory" in Portugal» (mimeografiado), The 1997 ESHET Annual Conference, Marseille, 27 Fevrier-2 Mars.

Beaud, M., y Dostaler, G. (1995): Economic Thought since Keynes. A History and Dictionary of Major Economists, Aldershot, Elgar.

Beltrán, Lucas (1993): Historia de las doctrinas económicas, Barcelona, Teide.

Beveridge, William (1945): Full Employment in a Free Society, New York, Norton.

Bini, Piero, y Macliulo, Antonio (1998): «The Reception of the "General Theory" in Italy (1936-1963)» (mimeografiado), The 1997 ESHET Annual Conference, Marseille, 27 Fevrier-2 Mars.

Calatayud, Salvador (1989): Capitalismo agrario y propiedad campesina. La ribera del Xúquer 1860-1930, Valencia, IVEI.

Cano Denia, Simón (1948): La teoria del interés en la Escuela de Estocolmo, Madrid, CSIC.

CAO-Pinna, Vera (1956): «El método de análisis de las interdependencias estructurales (Input-output Analysis)», Anales de Economia, núm. 62, septiembre, pp. 191-279.

- (1958): «Principales características estructurales de dos economías mediterráneas: España e Italia», Revista de Economia Política, núm. 1, vol. IX, enero-abril, pp. 23-112.

Caravale, G. (1992): «Keynes and the concept of Equilibrium», en Mario Sebas. TIANI (ed.), The Notion of Equilibrium in the Keynesian Theory, London, Macmillan, pp. 74-98.

Cardoso, José Luis (1994): «National Case Studies in the History of Economic Thougth. Lessons from the Portuguese Experience», en Manuela AlberTONE y Albertone Masoero (eds.), Political Economy and National Realities, Torino, Fondazione Luigi Einaudi, pp. 201-218.

CARDoso, José Luis, y LLUCH, Ernest (1999): «Las teorías económicas contempladas a través de una óptica nacional», en Enrique FuENTES QuiNTANA, Economía y economistas españoles, vol. I, Una introducción al pensamiento económico, Barcelona, Círculo de Lectores, pp. 477-484.

CASTAÑEDA, José (1958): Lecciones de teoría económica, Madrid, Aguilar.

Cavalierr, Duccio (1994): «Il corporativismo nella storia del pensiero economico italiano: una rilettura critica», Il Pensiero Economico Italiano, II/2, pp. 7-49.

Colander, David, y Coats, A. W. Bob (1989): The Spread of Economic Ideas, Cambridge, Cambridge University Press. 
Colm, Gérard (1965): «Política fiscal», en Seymour E. Harris (ed.), La nueva ciencia económica. La influencia de Keynes en la teoría y en la política, Madrid, Revista de Occidente, pp. 332-352.

Comín, Francisco (1996): Historia de la Hacienda, vol. I, España, Barcelona, Crítica.

Cotorruelo, Agustín (1976): «El profesor Torres Martínez y la política económica», en Revista de Económicas y Empresariales, núm. 2, enero-abril de 1976, pp. 177-186.

DARITY, Warren, y YOUNG, William (1995): «IS-LM: An Inquest», History of Political Economy, 27 (1), pp. 1-41.

DE CECCO, Marcello (1989): «Keynes and Italian Economics», en Peter A. HaLl, (ed.), The Political Power of Economic Ideas. Keynesianism Across Nations, Princeton, Princeton University Press, pp. 195-229.

EINAud, Luigi (1936): «Morale et Economie», Revue d'Economie Politique, pp. 289-311.

FigueroA, Emilio (1947): Teorias de los ciclos económicos, Madrid, Instituto Sancho de Moncada.

- (1965), Curso de política económica, Madrid, Revista de Derecho Privado.

FIsHER, Allan George Barnard (1946): «"Full Employment" and Income Inequality», The Economic Joumal, March, pp. 18-26.

Fornengo, Graziella (1997): «Vera Cao Pinna (1909-1986): un'antessignana dell'econometria in Italia», Storia del Pensiero Economico, núms. 33-34, pp. 159-182.

Fuentes IRURozqui, Manuel (1942): Tres ensayos sobre el nuevo orden económico, Madrid.

Fuentes Quintana, Enrique (1951): «Posible aplicación a la política económica española de la "Teoría General"», De Economia, Supl. monográfico núm. 1, pp. 130-143.

- (1976): «El profesor Torres Martínez y los problemas de la economía española», Revista de Económicas y Empresariales, núm. 2, enero-abril, pp. 167-176.

GAY, Vicente (1946): «Un reformismo no socialista (Una conversación con W. Beveridge)», Nueva Economía Nacional, núm. 444, 2 de mayo.

GIRÓN DE VELASCO, José Antonio (1945): La futura empresa de los seguros sociales. Discurso pronunciado por el Excmo. Sr. Ministro de Trabajo al tomar posesión de la Presidencia del Instituto Nacional de Previsión, Madrid, Publicaciones del Instituto Nacional de Previsión.

GonzÁlez, Manuel Jesús (1978): «Los economistas en el preludio de la planificación indicativà, Investigaciones económicas, mayo-agosto de 1978, pp. 121-156.

- (1979), La economía política del franquismo (1940-1970). Dirigismo, mercado y planificación, Madrid, 'Tecnos

- (1990): «Prólogo» a Manuel DE Torres Martínez, Obra escogida, FIES, pp. VII-LVIII.

GUIRAO, Fernando (1998): Spain and the Reconstuction of Western Europe 1945-1957, Houndmills, Macmillan.

Hall, Peter A. (1989): «Conclusion», en Peter A. Hall (ed.) (1989), The Political Power of Economic Ideas. Keynesianism across Nations, Princeton, Princeton University Press. 
HaRROD, Roy F. (1943): «Full Employment and Security of Livelihood», The Economic Journal, December, pp. 321-342.

Hicks, Ursula K. (1950): Hacienda Pública, Madrid, Aguilar.

Hirschman, Albert O. (1997): «Come la rivoluzione keynesiana fu esportata dagli Stati Uniti», en Albert O. Hurschman, Autosovversione, Bologna, Il Mulino, pp. 175-191.

ICE (1959): «La agricultura española y los problemas fundamentales de su desarrollo», Información Comercial Española, agosto, pp. 47-63.

IsARD, Walter, y CumBerLAND, John H. (1960): Regional Economic Planning. Techniques of Analysis for Less Developed Areas, Paris, European Productivity Agency.

KeYNES, John Maynard (1971) [1930]: Collected Writings, vols. V y VI, Treatise on Money, London, Macmillan.

- (1973) [1936]: Collected Writings, vols. VII, The General Theory of Employment, Interest and Money, London, Macmillan.

KNox, A. D. (1950): recensión a M. TORRES (1949), The Economic Journal, december, pp. 810-812.

LLUCH, Ernest (1980): «Sobre la historia nacional del pensamiento económico», «Introducción» a Álvaro Florez Estrada, Curso de Economía Política, Instituto de Estudios Fiscales, pp. vII.XxxIII.

- (1999): «Las historias nacionales del pensamiento económico y España», en Enrique Fuentes Quintana (dir.), Economia y economistas españoles, vol. I, Una Introducción al pensamiento económico, pp. 435-476.

MANOIILESCU, Mihail (1943): Teoría del proteccionismo y del comercio internacional, Madrid, 1943.

Marcuzzo, Cristina (1998): «From the "Fundamental Equations" to the "Effective Demand". Continuity or Change?», The 1998 ESHET Annual Conference, Bologna, 27 February-1 March.

Martínez Mesa, Francisco José (1997): El Consejo de Economía Nacional. Un estudio sobre el origen de la representación de los intereses económicos en el Estado español, Madrid, CES.

MEACCI, Ferdinando (1988): «The Principles of Capital in Luigi Einaudi's Work», Giornale degli Economisti, pp. 475-493.

Nueva Economía Nacional (1946): «El Profesor Sir William Beveridge, K. C. B.», $\mathrm{X}(440), 4$ de abril.

- (1946a): «Dos direcciones: Beveridge y Hayek», X (444), 2 de mayo.

OCYPE (1959): «Programa de ordenación de las inversiones», Documentación Económica, núm. 3.

Olesen, Finn (2001): «Jörgen Pedersen on Fiscal Policy. A note», IME Working Paper, 15/01, Department of Environmental and Business Economics, University of Southern Denmark.

Paris Eguilaz, Higinio (1938): El Estado y la economia. Política económica tota. litaria, Ediciones FE.

- (1945): Teoria de la economía nacional, Madrid, Instituto Sancho de Moncada.

PasinetT, Luigi, y SChefold, Bertram (eds.) (1999): The Impact of Keynes on Economics in the 20th century, London, Routledge.

PEACOCK, Alan Turner (1952): The Economics of National Insurance, London, William Hodge \& Co. Ltd. 
PEDERSEN, Jörgen (1945): Teoria y politica del dinero, Madrid, Aguilar.

PHILIP, Kjeld (1949): La Politica financiera y la actividad económica, Madrid, Aguilar. PSALIDOPOULOS, Michalis (1996): «Keynesianism Across Nations: the Case of Greece», The European Journal of the History of Economic Thought, 3:3, pp. 449-462.

RENAUD, Jean François (1997): «Le concept de déséquilibre dans l'analyse de J. M.

Keynes: la "Théorie Génerale" comme parenthèse dans la continuité d'une pensée», en The 1998 ESHET Annual Conference, Marseille, 27 février-2 Mars., mimeografiado.

RoBbINs, Lionel (1980) [1935]: Ensayo sobre la naturaleza y significación de la ciencia económica, México, FCE.

ROBERT, Antonio (1943): Un problema nacional: la industrialización necesaria, Madrid, Espasa Calpe.

ROBLEDO, Ricardo (1993): Economistas y reformadores españoles. La cuestión agraria (1760-1935), Madrid, MAPA.

SÁnchez ARBós, Andrés (1935): La teoría de la cantidad en Keynes y su posición en el Treatise on Money, Madrid, Documentación de la Junta de Ampliación de Estudios.

Sánchez Hormigo, Alfonso (1991): Valentín Andrés Álvarez. Un economista del 27, Zaragoza, Prensas Universitarias de Zaragoza.

SÁnchez RAMos, Francisco (1947): El descuento y la teoría del ciclo, Madrid, Instituto «Sancho de Moncada».

SCHNEIDER, Erich (1949): Contabilidad industrial, Madrid, Aguilar.

- (1958): Teoría económica, Madrid, Aguilar (2 tomos) [edición original ScHNEIDER, E. (1950): Einfübrung in Die Wirtschaftstheorie, I, Theorie des Wirtschaftskreislaufs, Verlag von J. C. B. Möhr, Tübingen].

SERPIERI, Arrigo (1925): La politica agraria in Italia e i recenti provvedimenti legislativi, Piacenza, Federazione Italiana dei Consorzi Agrari.

- (1929): Problemi della terra nell'economia corporativa, Roma, Edizioni del "Diritto del Lavoro".

- (1929a): Guida a ricerche di economia agraria, Roma, Ed. Fratelli Treves dell'ARI.

STONE, Richard (1954): «Input-output and the Social Accounts», en Tibor BARNA, Interdependence of the Economy, London-Milano, Willey-Giuffrè.

TINBERGEN, Jan (1939-1940): «Econometric Business Cycle Research», The Review of Economic Studies, vol. VI, pp. 73-90.

TIOE-54 (1958): Estructura de la economía española. Tablas Input-output, Madrid, Instituto de Estudios Políticos.

TORRES, Manuel de (1935): «Industrias nuevas e industrias viejas», Diario de Valencia, 27 de octubre.

- (1935a): «Por una política económico-agraria», Agricultura, marzo de 1935, pp. 242-243.

- (1943): Teoria general del multiplicador, Madrid, CSIC.

- (1944): El problema triguero y otros problemas fundamentales de la agricultura española, Madrid, CSIC.

- (1947): «Introducción» a J. JewkEs, Juicio de la planificación, Madrid, Aguilar, pp. XIII-XXII.

- (1949): Teoria de la política social, Madrid, Aguilar. 
- (1950): «Introducción» a K. Mandelbaum, La industrialización de los países atrasados, Madrid, Aguilar, pp. I-XXII.

- (1950a): «Introducción» a R. WALKER, De la teoría económica a la política económica, Madrid, Aguilar, pp. XIII-XXIII.

- (1953): La coordinación de la política económica de España, Madrid, Instituto Social León XIII.

- (1953-1955): «La relación dinero-precios», Anales de Economía, vol. XII-XV, núm. 49-60, pp. 34-57.

- (1955): Teoria y práctica de la política económica, Madrid, Aguilar.

- (1956): Juicio de la actual política económica española, Madrid, Aguilar.

- (1958): «Epílogo» a TIOE-54.

- (1960): «Prólogo» a Manuel DE TORRES (dir.), Relaciones estructurales y desarrollo económico. Las tablas Input-output como instrumento de la programación económica de España, Madrid, Organización Sindical Española, pp. xV.xxm.

- (1969): «Dictamen del profesor Torres», en César AlbIÑANA, pp. 167-182.

- (1969a): «Enmiendas del profesor Torres al Anteproyecto de Ley Articulada de mayo de 1954», en César AlbiñanA, pp. 183-206.

TORRES, Manuel de (dir.) (1958): Estudio econométrico sobre las repercusiones generales en los precios derivadas del aumento experimentado por las tarifas ferroviarias, Madrid, Consejo Económico Sindical.

TORRES, Manuel de, y LASUEN, José Ramón (1960): «Discussion paper», en Walter ISARD y John H. CuMBERLAND (1960), pp. 339-357.

TrEss, R. C. (1948): «The Diagrammatic Representation of National Income Flows», Economica, november, pp. 276-278.

VelasCo, Carlos (1984): «El "ingenierismo" como directriz básica de la política económica durante la autarquía (1936-1951)», Información Comercial Española, núm. 606, febrero.

Velarde, Juan (1968): Sobre la decadencia económica de España, Madrid, Tecnos.

- (1974): Introducción a la bistoria del pensamiento económico español en el siglo XX, Madrid, Editora Nacional.

- (1978): «Torres o la desmitificación necesaria», en Juan VELARDE, La larga contienda sobre la economía liberal. Discurso de recepción del académico de número Excmo. Sr. D. Juan Velarde Fuertes, Madrid, Real Academia de Ciencias Morales y Políticas.

- (1983): «Biblioteca hispana de Marx, Keynes y Schumpeter. Una primera aproximación», Papeles de Economía Española, núm. 17, pp. 374-416.

- (1988): «Keynes en España», en Rafael Rubio DE URQuía et al., Herencia de Keynes, Madrid, Alianza, pp. 102-126.

- (1990): Economistas españoles contemporáneos: primeros maestros, Madrid, Espasa Calpe.

VILLALONGA, Ignacio (1980): «El actual momento de la economía valenciana y su relación con el conjunto de la economía española», Conferencia pronunciada en el salón de actos del Instituto de Ingenieros Civiles el día 1 de junio de 1934, en Jordi PALAFOX (1980), Los años 30: crisis económica y derecha valenciana, Valencia, Almudín, pp. 105-133.

ZABALZA, Juan (1995): El pensamiento económico-agrario valenciano del siglo $\mathrm{xX}$ : Manuel de Torres 1930-1936, Instituto Juan Gil-Albert, Alicante. 
- (1998): El pensamiento económico de Manuel de Torres Martinez (1903-1960), Tesis doctoral inédita, Universidad de Alicante.

- (1998a): «Manuel de Torres y la imposición personal sobre la renta: una alternativa teórica a la "reforma tributaria silenciosa"», Cuadernos Aragoneses de Economía, Segunda Época, vol. 8, núm. 1, pp. 231-245.

Zagari, Eugenio (1982): «Introduzione» a Francesco D. Perillo y Eugenio ZaGarI (1982), La teoria economica del corporativismo, Napoli, ESI, pp. 13-59. 